\title{
Suspension: Disabling the City of Refuge?
}

Myria Georgiou, Suzanne M. Hall, Deena Dajani

Author's final version.

The definitive version of this article will be published in the Journal of Ethnic and Migratuon Studies.

May 2020

\begin{abstract}
This article focuses on suspension: a process and a politics in migration governance that disables subjects and destabilises the state. Drawing on migrant, civic actor and policy-maker insights and experiences in the cities of Athens, Berlin and London, the discussion reveals how suspension is operationalised and enacted. As recorded across three cities, suspension has become a way to govern migration as an unequal and racialised system by obscuring, prolonging and deferring state responsibilities and migrants' access to resources and rights. By focusing on who is most likely to be suspended, and how the urban convenes both everyday bordering and new solidarities, we aim to understand the politics of migration in a volatile political and economic conjuncture. Invoking the city of refuge as an actually existing but fragile ethico-political project, we critically reflect on the currency of urban politics of sanctuary cities as redemptive spaces detached from the punitive functioning of the state. We explore how suspension is operationalised in the city through three core processes: the fracturing of legalities; the devolution of care; and the spatialising of uncertainty. We further reflect on the precarious practices care and solidarity which engage our shared humanity as opposed to enforced differences.
\end{abstract}

\section{Keywords:}

Forced migration; city of refuge; sanctuary cities; European migration politics; borders 


\section{Introduction}

Images of the camp as a non-place governed by infinite temporariness have become familiar representations of suspended migrant lives. Less familiar are images and experiences of suspension among migrants ${ }^{1}$ occupying everyday urban spaces. In this paper we 'urbanise refuge' (Sanyal 2014) across the cities of Athens, Berlin and London. Drawing on transurban empirical research, we observe how suspension works as a displacement of space and time, positioning actors within the possibilities and limits of city space, while systematically rendering agency as hostage to uncertainty. In Athens, we encountered migrants indefinitely waiting to hear if their claims to refuge would be recognised so that they could move north. Such was the case of an Iraqi family, still living from suitcases after eighteen months in the city, holding on to an elusive hope that, any day, they would be allowed to travel to the Netherlands. In London, we observed the shared experience of many young newcomers from Syria, whose everyday precarity was exacerbated by denied access to education and healthcare. In Berlin, we met young refugees who presently live in dignity, having access to housing and education, but who agonise about their uncertain future and their chances for long-term settlement. Locating this discussion within the complex socio-political European geographies of migration, this article examines how suspension has become a differential but dominant process for managing people, rights and responsibilities. We argue that suspension is a technique and affect of governance that fractures legalities, decentralises provision, and spatialises uncertainty (Bagelman 2016). Moreover, we contend that suspension is an erratic and violent governmental process of interruption, that not only disables the subject but also the state.

By invoking the metaphor of the city of refuge we are compelled to intersect these structures of reception with an actually existing but fragile ethico-political project of solidarity and resistance. In locating our project in the city of refuge, we critically reflect on the currency of sanctuary cities as an urban politics that falls outside the punitive reach of the state. Our work on how the migrant, the city and the state become suspended connects the disabling processes of disruption that are endemic to the workings of European migration systems across scales

\footnotetext{
${ }^{1}$ We use 'the migrant' as an overarching concept to refer to people who have moved, either by force, need or desire, to a new place outside their place of origin. Most participants in this study moved as a result of forced migration, war and displacement. We do not divide participants between 'refugees' and 'migrants' as we are well aware that those categorisations shift within different political moments and they do not necessarily reflect individuals' self-identification or experience. For example, refugees from Afghanistan were recognised as refugees in 2015 but have been redefined as migrants in the context of EU's migration governance.
} 
of power. Drawing on a cross-European project conducted between 2018 and 2019 in Athens, Berlin and London (details following review), we analyse overlapping experiences of migrants, civic actors, service providers and policy-makers. Within these different practices and spaces, we encountered the complexities of receiving, disseminating, struggling to cope with, failing to deliver, being exhausted by, rhetorically maintaining, and waiting for refuge. The discussion that follows therefore situates the city of refuge in a compendium of highly unequal power geometries that structure reception. Despite the distinct challenges and expressions that emerged in Athens, Berlin and London, the study recorded a common thread that spanned the different geographies and power groupings of our research participants: a governmental process of suspension that undermines the city of refuge. This paper discusses the three dimensions of how this process of abeyance works and also how it is contested: a suspension of the subject; a suspension of the state; and fragile resistance to suspension through everyday solidarity.

\section{Theorising suspension}

Debates on suspended migrant lives and on the politics of waiting are not new to us. Critical migration and border studies have identified the precarious combination of state inaction in addressing migrant needs and rights, and its securitised action that determines migrant (im)mobility, especially for those who remain outside national or international juridicopolitical recognition (Fassin 2011; Squire 2011; Ticktin 2016). Those denied mobility justice (Sheller 2019) are confined by their status either as 'illegal migrants' or as unrecognised refugees, with their lives spatially and temporally suspended in borderlands, and even further beyond, for undetermined periods of time. In a regime where Europe pushes migrants as far away from its core as possible, and deliberately stalls their recognition, countries in the periphery, as well as others well outside migrants' desired destinations, become spatial and temporal 'zones of indistinction' (Agamben 1998). In these spaces, migrants' lives become perpetually suspended and their legal recognition remains limited: not only is their visibility hidden behind walls, but the banalisation of the camp in public imaginaries normalises securitised care (Chouliaraki and Georgiou 2019) and reduces state accountability (Menin 2017). As Oelgemöller (2011) puts it, these are spaces associated with migrants' metaphorical or real death. Waiting itself has become a liminal enforcement, caught between conflicting national and transnational governmental priorities. That means that the camp is frequently regulated through the reproduction of uncertainty - a reflection of the 
contradictory policies, which either on the basis of humanitarian protection or of securitised expulsion, keep migrant lives on the hold (Andersson 2014).

This disciplinary governance utilises techniques of separation and stratification that are gendered, racialised and classed. Mobility for example becomes gendered, with security forces, governments and the media inscribing gendered migrant categories, defining those who move as more aggressive and masculine against those who stay, conceived as feminised, passive, agentless (Conlon 2011). Furthermore, and with Europe's 'migration crisis' representing a powerful example, a racialised order of suspension becomes visible in the indeterminate confinement of 'non-white' bodies at the Greek island hotspots, as these are largely occupied by people from Africa and Asia. Hotspots' residents wait for months and years in confinement as their recognition is simply and indeterminately deferred (Joronen 2017). Patience and waiting become evidence of discipline within these spaces of indistinction, as impatience and frustration deem migrants threatening and ungrateful, attracting the state's punitive force (Andersson 2014; Trimikliniotis 2019). Resistance to suspension therefore works against migrants' chances for rights and recognition, displacing voice (Chouliaraki and Georgiou 2019) and reinforcing waiting as the dominant pathway out of desperation. In fact, 'stealing' migrants time (Peteet 2008) has become a weapon for deterring migration, not least through state's inactivity in processing migrant and refugee claims, or the lack of clarity in regulations that would enable migrants to access resources and rights (Bendixsen and Eriksen 2018; Bjertrup et al. 2018).

While suspension has been historically associated with the spatiality and temporality of the camp, it is now reproduced across time and space as a mode of migration governance that spreads outside, at, but also inside the border. As the present discussion expands its outlook beyond the space of the camp and of the borderland, it reveals the complex expressions and consequences of perpetuating suspension across urban, national and transnational spatialities and temporalities of migration. More specifically, our own analysis reveals how suspension is deployed as spatio-temporal discrimination and uncertainty (de Genova 2002; Trimikliniotis 2019). This becomes apparent in the differentiated European geographies of migration that implicate regions, nations and cities. For example, post- 'migration crisis", the EU reaffirms its internal divides by stalling or indefinitely freezing migrant mobility from its southern shores to its northern urban centres, consigning newcomers to the unresolved circuits of regulatory opacity and unending waiting (Bendixsen and Eriksen 2018). 
Within the European geographies of migration, the city becomes a prominent, even if unstable, space of suspension. Urban configurations of transit hostels and shelters, limited public services, and the temporality of rights turn cities into 'liminal territories', with rights becoming unclear and precariously determined (Papoutsi et al. 2019: 2200) as, at any point, migrants' access to housing, work and education can be redefined or withdrawn. Thus, suspension, as a differentiated but persistent spatio-temporal 'modern political technology of control' (Katz, Martin and Minca 2018: 4), is revealed in urban technologies of governance that fragment the subject, the state, and solidarity. For the migrant as subject, unclear and changing systems of rights and recognition, become stalling mechanisms that delay engagement with the wider society (Mountz 2011). For the state, weakening of service provision and diffusion of caring responsibilities among urban actors and the market results in erratic and unequally distributed care with detrimental effects for those who need it the most. For solidarity, resistance to those technologies of control comes through the generation of creative and collective action (Gray 2011; Smets 2019), that is, through performative acts of solidarity, which however remain fragile as the state and societal requirements for recognition are ever-changing (Butler 2015).

Suspension's dividing impetus disables the subject and disrupts the city of refuge, and as a regime of power is therefore contested in organised yet partial everyday acts of solidarity. The movement of Cities of Sanctuary, a central reference for our exploration of the city of refuge, is a complex and contradictory example, precisely as it attempts to destabilise suspension as a form of governance by securing spatio-temporal continuity for citizens, within a national context where migrants are stripped of this right. By promoting the unconditional 'right to the city' for all, Cities of Sanctuary project a collaborative politics of solidarity that contests states' requirement of citizens to become complicit to bordering (Squire 2017) with migrants suspended as outsiders. As we will show, however, the prospect of sharing the city through politics of solidarity and practices of care are full of structural compromises and deficiencies that reveal the uneven application of refuge (Bauder 2016). Indeed, some city of sanctuary initiatives themselves reproduce binaries of good-willing citizens and de-historicised, needy migrants (Squire and Bagelman 2012). As cities of refuge, welcome and collaboration remain incomplete, the challenge of recognition through troubling 'the hierarchical statist and pastoral categories of citizen/non-citizen and recipient/provider' 
(Squire and Bagelman 2012: 161) remains a project constantly tested and contested, as we discuss in this article.

\section{Three cities: a differential continuum of suspension}

In our study across the post-'migration crisis' cities of Athens, Berlin and London, we recorded how the city is implicated in migration governance. More specifically, and as we will show, the city reveals suspension as a differential continuum of power that disrupts agency, rights and recognition across both time and space. In our analysis, we build on and expand theorisations of suspension. Our aim is to show that we need to study the interweaving of uncertainties at the intersection of the realms of state, subject and collective solidarities to understand how migrant life and rights become splintered and unstable. Thus, we analyse how urban technologies of governance undermine the subject and the state, while also generating responses of deep but uneven commitments between newcomers and civic actors. Furthermore, and in order to understand suspension as a spatio-temporal process and politics, we analyse three dimensions of its constitution in relation to cities of refuge. First, and with a focus on the subject, we expand on the fracturing of legalities. We refer to fracturing legalities as the multiple forms of conditional citizenship and provisional refuge that substantially and continuously limit the terms of belonging, with recognition as always partial. Such limits establish deeply segregated systems of winners and losers, favouring the individual most capacitated to learn the national language, find work and navigate the city, by adopting the motif of 'the good migrant'. We observe the differentiated scales through which urban refuge is lived, for some a relative confinement to home, for others a more expansive space for exploration. Second, and with focus on the compromised affects of the suspended state, we examine how the state's devolution of care produces erratic, individualised and frequently depleted systems of support. Care is therefore situated within urban conditions of increasing inequalities, and the contrast in the provisions of welfare across Athens, Berlin and London prompt us to consider the denial of constitutive aspects of refuge, such as secure housing (Lafazani 2018). Third, and with focus on solidarity, we identify the spatialising of uncertainty occurring at the intersection of everyday bordering (Yuval-Davis, Wemyss and Cassidy 2019) and the persistent but precarious acts of shared civic recognition and action. The city has become a centralised site of border experimentation, evident in stateorchestrated hostile migration campaigns that additionally target migrant groups specifically in more marginalised parts of cities (Jones et al. 2017). In this context, everyday bordering divides citizens and newcomers who are made to compete for the city's overstretched 
resources by underscoring already procured ethnic and racial divides. Against those divides, configurations of solidarity that are often built on existing commitments to anti-racism, oppose the intersecting human and economic crises (Arampatzi 2017; Trimikliniotis et al. 2016). Thus we argue that both the processes of everyday bordering and its contestation through acts of solidarity are implicated in demarcating meanings and limits of suspension.

Although suspension is constitutive of migration governance across Europe, we position our analysis within the particular space and time of post-'migration crisis' in Athens, Berlin and London. The spatial focus is important within the hierarchal urban geographies of Europe, as different cities perform distinct geopolitical roles within the wider system of migration governance. The temporal context also matters, as European cities have become differentially situated at the intersections of the global financial crisis of 2008 and the 'migration crisis' of 2015-16, with European economic and migration politics converging around securitisation and marketisation. Aiming to understand structures of reception through the overlapping experiences of newcomers, civic actors and policy-makers in the engagement of refuge, we employed a multi-method approach. This included participatory workshops with migrants and civic actors (link to methodological tools after review); urban photographic storytelling walks with different actors of the city of refuge; and interviews with a number of urban and migration policy actors. The study took place across 2018 and 2019, at a time when ideologies and applications of neoliberalism and austerity profoundly shape practices of care and recognition. Whether austerity is externally imposed as in the case of Greece, or internally imposed as in the UK, the interlocking geographies of state authority at national, urban, and local scales have much to tell us about of how dramatically diminished public systems of care have significant consequences for the politics of recognition. While our analysis of the reciprocal disruption of care and recognition is rooted at the city-level in Athens, London and Berlin, the lived intricacies of the variable cities of refuge that we introduce below show how suspension is integral to migration governance in Europe.

\section{Athens: Perpetual temporariness}

Athens represents the first arrival city in many migrants' European journeys. Estimates show that it hosts half of the approximately 60,000 newcomers stranded in Greece since 2015 (UNHCR 2019). Athens as a city of refuge is constituted through a condition of perpetual temporariness. Structures of reception are fragile, while the state processes asylum and family reunification claims with extreme slowness that keeps thousands in waiting for months and 
often years. Temporariness reflects more than a deliberative state policy; it also reflects migrant imaginaries: almost everyone we encountered perceives Athens as a stopover in an incomplete journey which has Northern Europe as a final destination. The painful paradox here is that, while still holding on that imaginary destination, more and more migrants realise that Europe's internal borders are hermetically sealed, that red tape is a way to control migration through bureaucratisation, and that Greece is an inevitable, if undesired, destination. In this space-time of endless waiting, rights are recognised in principle but suspended in practice. The city has become a testing ground for the state's austerity policies and precarious politics of care, with migration policies aimed at containing newcomers but deliberately limiting access to its scarce resources, like housing and work. In this void, humanitarian organisations and grassroots groups are left to perform responsibilities of care, becoming themselves implicated in new forms of everyday bordering where care is detached from any prospect of long-term settlement and recognition. Such lack of clarity perpetuates migrant exclusion from housing and work, while fuelling despair among migrants and xenophobia among citizens against those strangers who hang on the elusive promise of leaving.

Within this regime of liminality, new forms of collective action have emerged. Athens' improvised governance means that rules of containment are constantly challenged: for example, temporary and informal housing, such as in the case of significant number of squats organised by anarchist and radical Left groups, offer migrants some security (though they themselves face the punitive power of the state). Illegal markets compensate for the lack of any other prospects for income, and networks of solidarity provide for what the state does not offer, including anything from internet connection to legal aid, health and food provisions. While Athens reflects the contradictions of neoliberal Europeanism, it encompasses an active process of city-making outside the strictures of state and market.

\section{Berlin: A conditional welcome}

The story of Berlin is one of apparent welcome and promise - seemingly the city closest to an ideal city of refuge. Berlin, has received more than 83,000 migrants since 2014 (McCarthy 2018), many of whom have been granted asylum. Berlin is strikingly different to the other two cities in this study, with substantial public investment in migrant welfare, education and digital connectivity - all under the umbrella of 'integration' policies. Here, the language of 'integration' constitutes a powerful normative framework that drives political and public 
investment in initiatives that are organised by the state and civil society. Those who are able and willing to 'integrate' are likely to find security and recognition, but recognition is always conditional on fulfilling a set of requirements: first, having legal status as a refugee is a prerequisite, a status only granted to a decreasing number of applicants; second, they need to have passed or be in the process of passing the demanding 'integration test', which includes a high standard German language exam; and third, they need to demonstrate existing skills or the ability to develop skills that are needed in the different sectors of the urban economy, especially the digital sector. As we repeatedly observed, the politics of integration are driven by the requirements of a performative refugeeness: a swift shift from a performed abject vulnerability (which was a requirement for arrival and settlement) to a performed entrepreneurial resilience (which has become a requirement for long-term access to rights). These requirements, as we observed, cause enormous anxiety among many migrants, who are uncertain about their prospects to succeed and have a future life in Germany.

\section{London: Tolerant invisibility}

With just over a third of London's population born outside of the UK, London as a city of refuge reflects the complex and uneven histories of its alterity. When we spoke to a Council official from a large London Borough that currently hosts eleven refugee families, we were informed that they keep a low profile about hosting the families to 'avoid negative publicity'. Indeed, the London case exemplifies how metropolitan governance is limited by a more hierarchical application of state border policy than in either Athens or Berlin, substantially constraining a city-level approach to refuge. The British Government only agreed to receive refugees post-2015 within the 'Vulnerable Persons Resettlement Programme', and newcomers are accepted on the basis of a humanity rendered as deprived. Newcomers who have found a home in London are numerically insignificant and their acceptance is, from the start, conditioned by the strictures of abject vulnerability. The 'Community Sponsorship Scheme' introduced by the Home Office in 2016, places the onus on community groups to act as private sponsors, taking on responsibilities of arranging housing, access to educational and medical services, and English language tuition. This responsibility is located in a city where housing is unaffordable for many, heightening the challenge of securing homes for newcomers. Additionally, stringent austerity measures have drained the infrastructures of care and public service provision. Within this strained context, we found that even those few newcomers' basic needs are often insufficiently met. 
This dehumanisation is not only exacerbated by a brutal politics of austerity, but is underpinned by migration governance, including policies to limit migration such as the 2012 'hostile environment' and the UK Immigration Acts of 2014 and 2016, ushering punitive legislation that promulgates the practice of devolved border control in the circuits of everyday life. These policies make it yet more difficult for migrants to access public services and housing. London therefore exemplifies the extremities of neoliberalism, concentrating in urban space a system of abjection in which stigmatisation, lack of affordable space and limited service provision prevail. Nonetheless, the expectations of the 'good migrant' as neoliberal subject, are evidenced here as well: newcomers can only gain permanent rights to stay in the UK if they pass language tests, security tests and also earn substantial income, all within five years of arriving. Thus, a high bar is set for newcomers: a performative refugeeness that requires a swift transition from extreme vulnerability to neoliberal competency. In outlining the spatio-temporal dimensions of this study above, we have argued that an urban-level analysis across Athens, London and Berlin helps to comprehend how borders and systems of refuge are organised across the related geographies of city and state. We now further substantiate our three frames of fracturing of legalities, the devolution of care, and the spatialising of uncertainty, by incorporating our field work material.

\section{Fractured legalities: the suspension of the subject}

The relational ways in which migrants, civic actors and state actors become suspended in the processes of refuge are constituted through the intensive delineation of insiders and outsiders in European border ideology. From the Brexit mantra of 'Take Back Control', to the Alternative für Deutschland campaign of 'Burkas? We like bikinis', the border is symbolically constituted through a pejorative outsider that reinforces cultural denial to recognition even when it is legally granted. Our study revealed how this suspension is performed and enacted through the everyday vetting of belonging, the surveillance of routines and language proficiencies and the ongoing assessment of skills and needs. We recorded how the fracturing of legalities around how refuge is recognised and enacted operates though the intersecting logics of racialisation and illegalisation. When we interviewed Gunter ${ }^{\mathrm{i}}$, an elected member of Berlin's Sozialdemokratische Partei Deutschlands (SPD) in 2018 he recounted: 'There is a return of a folk narrative, völkisch, where race is central. It was always there, but it's become like a landslide in what people say and what they think they can say'. While race-craft in relation to state-craft has a long history in Europe's relation to a constitutive outside, it has a particular permeation in the vocabularies of partial 
recognition or quasi-citizenship. In Germany, the historic establishment of partial citizenship regimes through the Gastarbeiterprogramm (guest worker programme) as a means to martial foreign labour from the 1950s to the 1970s, sits alongside the Duldung which literally translates to 'Tolerated Stay' and permits residency without the capacity to work. These quasi-citizenship regimes differentiate and discriminate groups on ethno-national grounds, and have explicitly affected Palestinian and Lebanese migrants who have been kept in the margins of the society for decades.

It is within this context of a hierarchy of rights relative to a hierarchy of subjects that Gunter went on to suggest the optimal paths to integration through work and language:

The best integration happens through day-to-day routines in the work place, in sports' teams, in the mastering of flirting [...] things have to be learnt in doing routines. But if you really want to arrive, language is the main key. For really arriving it is still necessary to speak German.

For the migrant, the conditionality of deservedness continuously shifts, while the expectations for integration and communication remain unidirectional. Between 2015 and 2019, the expected level of German newcomers required to obtain in order to get residency has risen significantly. We met Hamdi in Berlin, where he has been living since 2013. He is a university student, and works part-time as a German-Arabic translator. Hamdi described his encounter at a German-Arabic workshop where he was the translator and moderator:

A young German guy spoke up and said that 'it is great that refugees are speaking German and are working and creating their own income and paying taxes, but that is not enough, they need to integrate as well'...I don't really know what he meant, what does it mean to integrate? To look like him? I wanted to tell him: 'You know, I am the translator, if it weren't for me, you wouldn't have a voice, others in the room wouldn't even be able to know what you were saying, and you wouldn't be able to understand what others are saying either'.

During fieldwork, we became acutely aware of integration policies that privilege certain skills and systems of accreditation. The process of having to acquire new skills, despite previous training and accreditation, places a significant burden on the migrant, as it is not only a suspension of a future but also of a past. In one of our workshops hosted in Berlin, Raheem outlined the different ways in which personal past and previously acquired skills are 
narrowed to the point of redundancy. During the group discussions, Raheem used the image of a barrier to identify an obstacle, locating it on the worksheet used during the workshop to identify needs, resources and obstacles in building the city of refuge. He wrote next to the image: 'beginning from zero' and later explained:

It takes you around one-and-a-half to two years to achieve a basic understanding of the language, then another year to do a foundational programme so that you can be accepted into German universities, and then another four years at least for a Bachelor degree. So that is seven years of your life, usually eight, to be in the position you were at eight years ago.

An additional way in which the outsider is positioned is as a suspect of 'illegality' (De Genova 2002). For example, since the introduction of the UK's 2014 Immigration Act, 'sham marriages' and 'bogus students' are identified amongst the potential litanies of offence. In this same Act, an increasingly privileged space is reserved for the 'highly-skilled migrant', where class, gender and race are prominent in the designations of neoliberal citizenship. The growing designations of privileged and partial citizenships across Europe impact on cultures of refuge. When we first met Hadi in London in August 2018 he had just turned 21. He left Syria for Turkey when he was 16 and had been in the UK for just under nine months. He said:

I feel like I have to be the best representative of refugee possible... with organisations that help refugees, and with the Job Centre, so that they continue to support refugees and bring them over. So, I feel like I have to show that I am going to stand on my feet quickly, and will not be living on benefits, that I will work and succeed.

Hadi's narrative shows that he is well aware of the expectation to act within a set framework of performative refugeeness that constitutes him as deserving subject. His digitised profile at the Job Centre sets requirements for him to find employment and stable income while restricting his right to full-time education, something he longs for.

We also observed how these opportunities are even more restricted for those enmeshed with responsibilities of family care. In all three cities, we observed how women especially, as the primary carers for the young and the elderly, experience the city in restricted ways, with irregular access and little benefit from urban resources, such as language classes and digital training. While visiting a women's refugee centre in a council estate of East Berlin, we saw 
and heard from the social workers that the women using the centre are very unlikely to meet the requirement for residency, as their caring responsibilities make it impossible to fully devote to learning the language and new skills - the high bar set to them by the state for recognition. Civic actors participating in a workshop we organised in Berlin also emphasised the different temporalities of migrant experience that become collapsed within singular, linear systems of 'integration' imposed by the state: "psychological arrival" does not take place at the same time for everyone', we were told, 'but services to not provide for difference'.

As these experiences reveal, access to rights and recognition is inflexible and subjected to newcomers' own performance as 'good migrants', willing and able to swiftly integrate into the market and the mainstream society, while succeeding to do so with little or no support from the state. At the same time, this is a volatile system as it is always subjected to the changing temporality of the state's and the market's requirements. For example, while Europe experienced a moment of ecstatic humanitarianism in the autumn of 2015, with borders opening to many seeking refuge, they swiftly shut when Europe reverted to its bordering policies of intense securitisation after the November 2015 Paris terrorist attacks (Chouliaraki, Georgiou and Zaborowski 2018). In this context of fractured legalities, migrants' present and future remain uncertain, tied to the erratic temporalities that reproduce their quasi-status and limited recognition. Such systems of recognition are dependent on both legal and cultural expectations of belonging, as much as the instrumental demands of fluctuating state ideology and market demands. Recognition is therefore interrupted by the discriminatory and erratic applications of who is to be recognised, at what point and to what extent.

\section{Devolving care: the suspension of the state}

The fragmented legalities of refuge and citizenship we observed, especially in London and Athens, intersected with an abundant set of legislations and programmes around austerity and the devolution of care. Austerity shares with the fragmented legalities of refuge 'techniques of sorting populations and the machinery of carefully variegated dispossession' (Bhattacharyya 2015: 29). In London the austerity programme explicitly shapes systems and experiences of refugee and asylum seeker care and support. A Syrian family resettled through the 'Vulnerable Persons Resettlement Programme' told us that no social worker visited them for the first eight weeks after their arrival. They did not speak English, and the father who 
needed medical care was unable to access it until two months later, when an Arabic-speaking support worker eventually visited. The responsible local Council has had to cut staff numbers down by nearly half since the beginning of the austerity programme. Another family with a severely disabled daughter, had to wait for eight months for an appointment to have their daughter measured for a tailor-made wheelchair. It took a further three months for her to receive the wheelchair. Stranded on the floor, unable to move at all, the young woman was cared for by her mother, whose mobility was also inevitably constrained. During fieldwork, we became well aware of how 'the gendered differences in mobility' (Kofman 2019: 2186), alongside the state's reduced capacity of care, directly impact and exacerbate suspended lives.

Austerity shapes not only migrants' everyday lives, but also the experiences of support workers and civic actors who support them. Exhaustion emerged as a repeated theme in the words of people we meet, resulting from devolved care provision. Sanaa has lived in London for 30 years and when we met her, she was working for a corporate care provider hired by a London Borough to provide social care work for new migrant families. Outsourcing public services to corporate providers has become a growing trend in the provision of care to newcomers. The privatisation of care comes at a cost, both for those working in the sector and those receiving its services. Sanaa's desperation was made clear to us:

I feel I am completely on my own, I just fill out timesheets with the hours I spend with each family and they send me my money. That's it. Nothing else at all. No support at all. I am a freelancer. I am meant to be supporting five families now, but I am also still supporting five others I was supporting before. The agency [referring to the care provider she works with] said there was no more support for these families, but they call me for everything, every little thing. My phone is always ringing [and when I don't attend to them] they make me feel bad, and that upsets me so much. My friend told me I need to have boundaries, and I do try, but am so tired. So tired.

In the context of austerity-hit Athens, activists, volunteers and NGOs have largely taken over care, following the almost full collapse of state welfare provisions post-2008 financial crisis. In this city, the consequences of regional and global inequalities expand across the emotional and material labour done by those providing care - uniting them and dividing them at the 
same time and reinforcing new hierarchies within structures of mobility injustice. An activist and teacher in an Athens school, which mostly educates migrant children, painfully observed:

There is a difference between people who come here to work in NGOs or organisations - thousands of people doing many great things - but there is a difference connected to time. I am a local. All the drawbacks that we have been describing [in relation to austerity] have been part of my life and everybody's life in Greece. I am not planning to leave and go to another country to do something else. [...] I get more easily depressed because I'm living with these pressures across a dozen different issues of many variations. So, it is different, actually. You are passing by somehow [looking at us]. This is also serious. Flowing flows of immigration and flowing flows of people from western countries. You build connections with both and make friendships and then you go. And we are left with a sense of loss.

In contrast to London and Athens where vulnerabilities are evident across the spectrum of care, Berlin has a committed base of public funds that support a range of services, from language classes, skills development and cultural projects and well-being initiatives. Yet public service provision in the city are driven by a neoliberal ethos, projecting discourses of the resilient, entrepreneurial and grateful migrant as the desired subject. Enaya, a Palestinian migrant activist, active in Berlin since the 1970s, told us how the pressures on newcomers is substantial; their recognition, she explained, is tied to their compliance. As she argued, care comes with locals' expectation of gratitude by newcomers, an expectation that further pressurises newcomers:

The problem with the welcoming environment was, it was not supported. People in Germany hosted people in their homes, without being prepared on how to deal with trauma. They were expecting people to come to them, stay in their houses, and to say 'thank you so much!'. Be grateful and thankful all the time. Hosts became frustrated that refugees appeared to them 'ungrateful'... There was no understanding of...conflict, of having to make sense of what they just experienced and what they are now receiving. There was rage and anger. The newcomers didn't have the leisure of nice and grateful. They were going through so much... The expectations of the hosts were so wide off the mark...I believe the welcoming attitude was genuine, but not supported in an appropriate way. It was a missed opportunity. 
The examples above point to systems of care from which the state has increasingly withdrawn and in which the receiving of care immerses in a moral trope. The mutual formation of care as a reciprocal process of learning and recognising is thus substantially reduced. Rather, the onus is devolved to overstretched social workers and those who provide support out of solidarity, and to the moral standing of migrants, whose physical and emotional capacities have been worn thin by trauma and uncertainty. Ansem de Vries and Gould identify a " "politics of exhaustion" to highlight the impact and protracted character of this violence' (2019: 2157) that state-induced uncertainty systematically subjects migrants to. Our study has revealed how the suspension of care operates through the delineation of responsibility. The depletion of state resources means the devolution of care is frequently individualised, resulting in the exhaustion of unsupported care workers and activists. At the same time, core state infrastructures of care once embedded in the provision of social services through local authorities have been substantially suspended by austerity measures.

\section{Spatialising uncertainty: divided cities, solidarity cities}

The deferrals of responsibility discussed above reflect a logic of suspension that allows us to conceptualise the relationship between migration governance and urban space as everyday and proximate. Unlike the spaces of exception of the camp and the detention centre (Agamben 1998), where the spectre of the migrant is held at a distance, suspension provides a quotidian view of how variegated dispossession happens in everyday life in shared space. By attending to both technologies of austerity and suspension, what emerges is a process of 'shaping and re-shaping space, through the differential regulation of subjects that come to experience shared space in fundamentally different ways' (Dajani 2020: 7). In the city, suspension takes hold spatially in the everyday life of schools, doctors' surgeries and streets in urban neighbourhoods. In these unexceptional realms, the city exemplifies a spatial and political geography of 'everyday bordering' shifting from migration policy as management of transnational mobility to a holistic project for governing citizenship rights and politics of belonging within spaces of co-existing difference (Yuval-Davis, Wemyss and Cassidy 2019). The pervasive expanse of borders requires us to explore the differing spatial compositions of how the decentralisation of migration control intersects with the reduction and outsourcing of care. In opposition to the exacerbation of fear are the remakings of civic care, both tenuous and creative. However, here our research points to both differing and differentiating spaces of refuge, extending from the urban camp to the urban neighbourhood. As we have discussed, it 
is not only these spaces that confer the varied possibilities of recognition or solidarity, but also the gendered and racialised space of the body and the relative im/mobility this confers.

Containment, as a spatial process of securisting and enforcing mobility emerged as a central narrative. When we met Ahmed in Athens, he had been in Greece for more than a year and was living in the urban camp of Eleonas. We spent a day with him, after which he invited us to his home in Eleonas camp, a space he describes as his 'container'. While we were there, he talked about the institutional order of everyday life in the camp, where camp residents are captive subjects for scrutiny and intermittent volunteerism:

There is an advantage of living here [in the camp]. I met people from so many organisations. So it helped me create networks. So it is better than an apartment...Still, there are things that happen in the camp that are annoying. So many times this happened to me: I was sitting with my neighbours in front of our containers having tea and chatting or something, and you see people from organisations walking around, looking at us, watching us. We are not creatures in a zoo! C'mon! Or you see the volunteers that come and they spend a day just to take photos and say "we are doing something for refugees".

In addition, the space-time of the camp is innately ambiguous, suspending mobility through strict regulations around movement, while providing a liminal territory for those whose fate is tied to lengthy and erratic decision-making processes. Ahmed hasn't seen his wife or daughters since 2016 and although he has been granted asylum in Greece, this status has not liberated him from the uncertainty that, to him and many others, seems eternal. While family reunification is one of multiple EU commitments associated with asylum, the intense bureaucratisation of the process prevents its actual realisation with thousands waiting for years with no timeline or resolution.

This suspension of certainty is differentially spatialised in the urban context of Athens, Berlin and London. While everyday life is fundamentally governed by an extended temporality, in the city of refuge it is partly about providing a relative base of stability, which is frequently conditioned by how space and time - most notably through secure housing - is officially designated. In our research we were aware how a national political economy around social housing profoundly affects the relative uncertainty which inscribes refugee life, and also shapes the kinds of solidarity that emerge in each context. For example, networks of squats 
have grown across Athens since 2015, precisely as newcomers have been stranded in the city, uncertain about their right to move and unsupported by the state in their attempt to find security. These squats emerge out of historical claims to housing in city where housing estates, 'have never formed a sector of the housing stock serving the needs of the most vulnerable population groups.' (Kandylis, Maloutas and Myofa 2018: 77). In Berlin, stable housing for refugees has been better organised through existing infrastructures of metropolitan social housing provision, even though selectively supplied to certain newcomers and denied to others. It is frequently through these state or state-endorsed networks that resources, recognition and solidarities are formed. In London, housing provision for refugees is severely curtailed by a nationalist neoliberalism that has profoundly limited the housing supply process through the localised and individualised 'Community Sponsorship Scheme'. This scheme is dependent on accessing the private rental market, in a city where private rents have significantly increased since 2011. The unrealistic expectation that refugees should be self-sufficient after two years of support, brings the spectre of uncertainty into the space of the home. Unsurprisingly, much of the solidarity practices we witnessed occur across the fragments of diminished state resources.

Solidarity networks therefore operationalised different spatial practices in relation to the underlying context of how everyday borders are governed and what resources are available for creative collective action. In Berlin a group of newcomers set up their own makeshift Arabic library that has since been incorporated into the City Library. In London, against the lack of public support for training that would enable newcomers to move from precarity to employment, coding schools, such as the 'Code your Future' in London, have been set up as grassroot projects without state funding, to support those who hope to find employment in the digital economy. In this narrowly-designated spaces of freedom, Hadi responds by generating tactics of everyday resistance: engaging with urban cultures of solidarity, he gets access to some opportunities to live with dignity. For example, through a Facebook initiative he secured a free bike, which he rides around the city equipped with Googlemaps and he attends free coding classes offered to refugees. Resilient, determined and able to perform 'the best representative of refugee possible' Hadi benefits from urban politics and technologies that give him hope for recognition. In Greece, a mobile platform provides much needed legal advice in four languages. Against limited access to legal support and health across all cities, law and health solidarity networks have set up provisions of information and care, irrespective of the legal status of those seeking support. Within urban contexts where shared 
space is characterised by the limits of official care, and where different groups of residents are held in varied degrees of suspension, small and unheroic solidarities emerge between people. Newcomers in Berlin print their own Arabic language newspaper addressing migrant and local issues, generating a voice and revitalising local public micro-spheres. A refugee struggling with an old manual wheelchair received a new electric one from a fellow Londoner he spoke to briefly at the local mosque during Friday players. These small acts in the micropublics of fraught urban life testify to a spirit that is more expansive than the forms of suspension acted upon it, but also surface the fragile and partial spaces of solidarity in urban contexts where the state provision of resources recedes alongside the privatisation and individualisation of care.

\section{Conclusions: Suspension, delimiting the city of refuge}

Across the span of our study, we became acutely aware of the spatio-temporal reproduction of uncertainty and narrowed possibilities for settlement and recognition for migrants: a process and a politics of suspension that expand the fragility of the subject, the state, and solidarity in the city of refuge. Across the three cities, we were able to explore these fragilities, in relation to three processes respectively: fractured legalities, devolved care, and spatialised uncertainties.

The fracturing of legalities is reflected in the unstable system of rights that deems certain migrants as worthy of recognition, while indefinitely perpetuating others' precarity and insecurity. Thus, migrant life becomes conditioned upon the complex geopolitical spatiality of migration that divides urban actors and the biopolitical temporality that perpetuates migrants' otherness. As the certainty of recognition is missing from the lives of many but the surveillance of their compliance is always present, the possibility of ordinariness becomes extraordinary. Instead, migrants constantly need to respond to never being quite settled, never quite belonging, never being fully recognised by trying to develop skills that deem them worthy of security and settlement in the city.

The devolution of care reveals the contradictory affects of the state's suspension: caught between care and exhaustion, and solidarity and abandonment, the actors of the city of refuge find themselves responding to a politics of migration driven by securitization of everyday life 
and marketization of care. While migration governance increasingly hyper-delineates the border and expandes it across the spatiality of the city and the temporality of everyday life, it also devolves the core state functions of care and diffuses caring responsibilities across the city and its actors, exhausting civic resources and agency. This paradoxical combination of hyper-controlled borders and disorganised care is brought to life through macro-level processes (policies) and micro-level effects (everyday life). Its consequence is the production of an affective governmentality where care is managed through racialized and gendered hierarchical structures that exhaust and divide between the actors of the city of refuge.

Uncertainty is spatialised through everyday bordering in the city. As everyday bordering implicates governmental, nongovernmental and citizen actors in managing and disciplining migrants, they raise even more obstacles to migrant engagement in the society and perpetuate their suspension and uncertainty. As everyday life in the city becomes a site of discipline and control of migrant bodies, it also generates resistance, not least through everyday acts of solidarity that challenge bordering acts and discourses in the city. Acts of everyday solidarity push back against everyday bordering, sometimes successfully and sometimes unsuccessfully. In the city, migrant everyday life is delimited through the stigma of the outsider, but it is also enacted through agency and solidarity involving a wide spectrum of those who share urban space. In our study, this was observed in different inhabitations of spaces of refuge, not least informal housing and training projects, solidarity health and legal advice clinics. But our study also revealed how actors of solidarity themselves become implicated in bordering, especially when they reproduce narrow systems of recognition that only recognise migrants as vulnerable others in need of temporary care.

The perpetual suspension of migrants in the city reveals the ideological disruptions within the multi-scalar, interlocked geographies of migration governance that deliberately detach global power asymmetries from forced migration and urban diversity from histories of colonialism. Migration to the city is interweaved in geographies and histories of regional violence and involuntary mobility, not least those generated through colonialism and perpetuated dependencies and divides of North/South; rich/poor; citizens/noncitizens (Hall 2017). As national and EU governance detaches migration from Europe's responsibilities in destabilising economy and politics in migrants' countries of origin, migrants become reduced to dehistoricized subjects determined through Europe's benevolence (humanitarianism) or Europe's threatened wellbeing (securitisation). Reduced into vulnerable or threatening 
Others, migrants need to constantly prove their right to a life beyond suspension and to effectively confirm that they are neither a burden nor a threat to the national community by swiftly turning from vulnerable others to neoliberal insiders. In this context, city becomes the performative space of evidenced transformation, monitored by citizens and the state's systems of surveillance. But the city is also unsettled and diverse: a site for the state to roll out and test migration controls, it also contests them. Thus the city occupies a paradoxical place in the politics of suspension: everyday solidarities emerge through the ordinariness of encounters and proximity between the actors of the city of refuge; at the same time, proximity enhances the divisive, affective governmentality of migration, as urban actors have to compete for limited resources within racialised and gendered hierarchical systems of urban governance and economy. Consequently, the city is refuge remains a fragile but important ethico-political project: within it, struggles for rights and recognition are as much struggles for resources, as they are for dignified life. 


\section{References}

Agamben, Giorgio. (1998) Homo Sacer. Stanford: Stanford University Press.

Andersson, Ruben. (2014) Illegality, Inc.: Clandestine migration and the business of bordering Europe. Berkeley: University of California Press.

Ansems de Vries, Leonie and Elspeth Guild. (2019) 'Seeking Refuge in Europe:

Spaces of transit and the violence of migration management'. Journal of Ethnic and Migration Studies, 45(12): 2156-2166.

Arampatzi, Athina. (2017) 'The Spatiality of Counter-austerity Politics in Athens, Greece: Emergent "urban solidarity spaces"”. Urban Studies 54(9): 2155-2171.

Bagelman, Jennifer. (2016) Sanctuary City: A suspended state. New York: Palgrave MacMillan.

Bauder, Harald. (2016) "'Sanctuary Cities: Policies and practices in international perspectives'. International Migration 55(2): 174-187.

Bendixsen, Synnøve. and Thomas H. Eriksen. (2018) "Time and the Other: Waiting and hope among irregular migrants.” In Manpreet K. Janepa and Andreas Bandak (eds.) Ethnographies of Waiting: Doubt, hope and uncertainty. London: Bloomsbury, pp. 87-112.

Bhattacharyya, Gargi. (2015) Crisis, Austerity, and Everyday Life: Living in a time of diminishing expectations. London: Springer.

Bjertrup, P.J., Malika Bouhenia, Philippe Mayaud, Clément Perrin, Jihane Ben Farhat, Karl Blanchet (2018) A life in waiting: Refugees' mental health and narratives of social suffering after European Union border closures in March 2016, Social Science \& Medicine, 215 (5360).

Butler, Judith. (2015) Notes Toward a Performative Theory of Assembly. Harvard: Harvard University Press. 
Conlon, Dierdre .(2011) 'Waiting: Feminist perspectives on the spacings/timings of migrant (im)mobility'. Gender, Place \& Culture, 18(3): 353-360.

Chouliaraki, Lilie and Myria Georgiou (2019) Borders, in (eds.) Kevin Smets, Koen Leurs, Myria Georgiou, Saskia Witteborn and Radhika Gajjala. The Sage Handbook of Media and Migration. London: Sage.

Chouliaraki, Lilie, Georgiou, Myria and Zaborowski, Rafal, with W. Oomen (2017) Final report: The European 'migration crisis' and the media. A cross-European content analysis. Retrieved from: http://www.lse.ac.uk/media-andcommunications/assets/documents/research/projects/media-and-migration/Migration-andmedia-report-FINAL-June17.pdf

De Genova, Nicholas. (2002) 'Migrant “Illegality” and Deportability in Everyday Life'. Annual Review of Anthropology 31(1): 419-447.

Dajani, Deena. (2020) Refuge under austerity: The UK's refugee settlement schemes and the multiplying practices of bordering. Ethnic and Racial Studies, DOI: $10.1080 / 01419870.2020 .1715453$

Fassin, Didier. (2011) Policing borders, producing boundaries: The governmentality of immigration in dark times. Annual Review of Anthropology, Vol.40, pp. 213-246.

Gray, Breda (2011) Becoming non-migrant: lives worth waiting for, Gender, Place \& Culture 18:3, 417-432, DOI: 10.1080/0966369X.2011.566403

Hall, Suzanne M. (2017) 'Mooring 'Super-diversity' to a Brutal Migration Milieu'. Ethnic and Racial Studies 40(9): 1562-1573.

Jones, Hannah, Yasmin Gunaratnam, Gargi Bhattacharyya, William Davies, Sukhwant Dhaliwal, Emma Jackson, and Roiyah Saltus. (2017) Go Home?: The politics of immigration controversies. Manchester: Manchester University Press.

Joronen, Mikko. (2017) 'Spaces of Waiting: Politics of precarious recognition in the occupied West Bank'. Environment and Planning D: Society and Space 35(6): 994-1011. 
Kandylis, George, Maloutas, Thomas, and Niolina Myofa. (2018) 'Exceptional Social Housing in a Residual Welfare State: Housing Estates in Athens, Greece'. In: Hess D., Tammaru T., van Ham M. (eds) Housing Estates in Europe. London: Springer.

Katz, Irit, Diana Martin and Claudio Minca. (2018) Camps Revisited: Multifaceted spatialities of a modern political technology. London: Rowman \& Littlefield.

Kofman, Eleonore. (2019) 'Gendered Mobilities and Vulnerabilities: Refugee journeys to and in Europe'. Journal of Ethnic and Migration Studies, 45(12): 2185-2199.

Lafazani, Olga. (2018) 'Homeplace Plaza: Challenging the border between host and hosted'. South Atlantic Quarterly 117(4): 896-904.

McCarthy, Naill (2018) 'Germany is Home to the Most Refugees'. In Statista. https://www.statista.com/chart/14494/germany-is-home-to-the-most-refugees/

Menin, Laura. (2017) 'Suspended Lives: Undocumented migrants' everyday worlds and the making of 'illegality' between Morocco and Italy'. In Gaibazzi, Paolo, Dünnwald, Stephan and Alice Bellagamba. (eds.) EurAfrican Borders and Migration Management, pp. 263-282. New York: Palgrave Macmillan.

Mountz, Alison. (2011) 'Where Asylum-seekers Wait: Feminist counter-topographies of sites between states'. Gender, Place \& Culture 18(3): 381-399.

Oelgemöller, Cristina. (2011) "'Transit" and "Suspension": Migration management or the metamorphosis of asylum-seekers into 'illegal' immigrants'. Journal of Ethnic and Migration Studies, 37(3) 407-424.

Papoutsi, Anna, Painter, Joe, Papada, Evie and Antonis Vradis .(2019) 'The EC Hotspot Approach in Greece: Creating liminal EU territory'. Journal of Ethnic and Migration Studies, 45(12): 2200-2212.

Peteet, Julie. (2008) 'Stealing Time: Waiting, the politics of time in Palestine'. Middle East Report 248. 
Sanyal, Romola. (2014) 'Urbanising refuge: Interrogating spaces of displacement'. International Journal of Urban and Regional Research 38(2): 558-572.

Schuster, Liza. (2011) 'Dublin II and Eurodac: Examining the (un)intended(?) consequences'. Gender, Place \& Culture,18(3) 401-416.

Sheller, Mimi. (2018) Mobility Injustice: The politics of movement in an age of extremes. London: Verso.

Smets, K. (2019). Media and immobility: The affective and symbolic immobility of forced migrants. European Journal of Communication, 34(6), 650-

660. https://doi.org/10.1177/0267323119886167

Squire Vicky. (ed). (2011) The Contested Politics of Mobility. Borderzones and Irregularity, London, Routledge.

Squire, Vicki and Jennifer Bagelman. (2012) 'Taking not Waiting: Space, temporality and politics in the City of Sanctuary movement'. In Nyers, Peter and Kim Rygiel (eds.) Citizenship, migrant activism and the politics of movement, pp. 158-176. Routledge, 2012.

Trimikliniotis, Nicos (2019) Migration and the Refugee Dissensus in Europe. London: Routledge

Trimikliniotis, Nicos, Dimitris Parsanoglou and Vassilis S. Tsianos. (2016) 'Mobile Commons and/in Precarious Spaces: Mapping migrant struggles and social resistance'. Critical Sociology 42(7-8): 1035-1049.

Ticktin, Miriam. (2016) Thinking beyond humanitarian borders, Social Research: An International Quarterly, Vol.38(2), pp. 255-271.

UNHCR (2019) Factsheet: Greece. https://data2.unhcr.org/en/documents/download/72479

Yuval-Davis, Nira, Georgie Wemyss, and Kathryn Cassidy (2019) Bordering. Cambridge: Polity.

\footnotetext{
i Pseudonyms are used for research participants, in line with the project's research protocols.
} 